Federal Reserve Bank of Dallas

Globalization and Monetary Policy Institute

Working Paper No. 308

https://www.dallasfed.org/ /media/documents/institute/wpapers/2017/0308.pdf

\title{
Exploring the Nexus between Inflation and Globalization under Inflation Targeting through the Lens of New Zealand's Experience ${ }^{*}$
}

\author{
Ayşe Kabukçuoğlu \\ Koç University \\ Enrique Martínez-García \\ Federal Reserve Bank of Dallas \\ Mehmet Ali Soytaş \\ Özyeğin University
}

March 2017

\begin{abstract}
We investigate empirically the inflation dynamics in New Zealand, a small open economy and a pioneer in inflation targeting, under various open-economy Phillips curve specifications. Our forecasting exercise suggests that open-economy Phillips curves under standard measures of global slack do not help forecast domestic inflation, possibly indicating measurement problems with global slack itself. In turn, under a stable inflation target we still find that (i) global inflation and (ii) global inflation and oil prices have information content for headline CPI and core CPI inflation over the 1997:Q3-2015:Q1 period and appear to be reliable proxies for global slack in forecasting inflation.
\end{abstract}

JEL codes: C21, C23, C53, F41, F47, F62

\footnotetext{
* Ayşe Kabukçuoğlu, Koç University, Rumelifeneri Yolu, İstanbul, 34450 Turkey. akabukcuoglu@ku.edu.tr. http://aysekabukcuoglu.weebly.com. Enrique Martínez-García, Federal Reserve Bank of Dallas, 2200 N. Pearl Street, Dallas, TX 75201. 214-922-5262. enrique.martinezgarcia@dal.frb.org. https://sites.google.com/site/emg07uw. Mehmet Ali Soytaş, Özyeğin University School of Business, Room 350, Çekmeköy, İstanbul, 34994 Turkey. mehmet.soytas@ozyegin.edu.tr. https://faculty.ozyegin.edu.tr/mehmetas. We acknowledge the excellent research assistance provided by Valerie Grossman. We also thank Paolo Surico for sharing his Matlab codes. The views in this paper are those of the authors and do not necessarily reflect the views of the Federal Reserve Bank of Dallas or the Federal Reserve System.
} 


\section{Introduction}

The Phillips curve, in its broadest sense, postulates a trade-off between real and nominal variables. This relationship remains one of the cornerstones to understand inflation dynamics and for policy to this day. ${ }^{1}$ However, Atkeson and Ohanian (2001), among others, have argued that the empirical evidence on the validity of Phillips curve-based models is weak for forecasting U.S. inflation. Atkeson and Ohanian (2001) show that during the Great Moderation period Phillips curve-based models often underperform naïve models (i.e. models that are based on past realizations of inflation alone). We argue, however, that it is important to recognize the potential misspecification of conventional closed-economy Phillips curve-based forecasting models such as those investigated by Atkeson and Ohanian (2001) in a world that has become increasingly more integrated-through trade in goods, capital, labor, information, etc.

A strand of the literature has emerged articulating the so-called global slack hypothesis which postulates that the relevant trade-off in an increasingly interconnected world is between domestic inflation and global (rather than domestic) real economic activity. This literature has explored the role of global slack measures and related global indicators in explaining and forecasting inflation and has documented these patterns across a large group of advanced economies (not just for the U.S.). For instance, Kabukçuoğlu and Martínez-García (2016a,b) provide both theoretical and empirical evidence on the significance of global forces for forecasting domestic inflation for the U.S. as well as for a group of 14 advanced economies.

The existing evidence suggests that a more complete theoretical framework for inflation forecasting can be constructed on the basis of an open-economy (rather than a closed-economy) Phillips curve. Our work in this paper is partly motivated by that empirical insight. We are also motivated, on the one hand, by the existing theoretical literature on the global slack hypothesis which posits that it is global, and not solely domestic, economic slack what drives domestic inflation (Martínez-García and Wynne (2010)). On the other hand, we are also spurred by the ongoing debate among policy-makers about the role of globalization for the conduct of monetary policy (Bernanke (2007), Fisher $(2005,2006)$, and more recently Draghi (2015), Kaplan (2017))..$^{2}$

In this study, we explore the relationship between globalization and the inflation dynamics for the case of New Zealand since the beginning of the 1980s. New Zealand is an open economy and a pioneer in inflation targeting, from which important lessons about the role of this monetary policy framework can be learned. ${ }^{3}$ We take into account the misspecification of

\footnotetext{
${ }^{1}$ The idea behind the Phillips curve is credited to William Phillips, a New Zealand economist, who in 1958 suggested a short-term relationship between wages and unemployment using data from 1861 to 1957 from the United Kingdom. It seems all the more fitting to note this here given our focus on the Phillips curve relationship as it applies to Phillips' home country. However, it is less well-known but not less true that the first statistical investigation of the relationship between inflation and the unemployment rate can be found much earlier Fisher (1926)'s work using U.S. data for the period from 1903 to 1925.

2 Draghi (2015) highlights the importance of the nexus between globalization and domestic inflationwhereby inflation is becoming less responsive to domestic factors and, instead, increasingly driven by global factors. Kaplan (2017) writes on recent developments in U.S. inflation about global slack emphasizing that, in his view, "(...) in a more interconnected world, excess capacity outside the U.S. may be dampening inflation pressures in the U.S."

3 Inflation targeting was introduced in New Zealand in December 1989. The legal framework was established by the Reserve Bank of New Zealand (RBNZ) Act 1989 which specifies that the primary function
} 
closed-economy Phillips curve-based forecasting models arising from globalization-i.e., the greater openness of an economy-focusing explicitly on the interlinkages of the New Zealand economy with the rest of the world.

In particular, in this paper we evaluate how the spatial dimension of international economic activity helps understand and forecast New Zealand inflation. The theoretical and empirical insights that underpin this paper follow closely in the footsteps of Martínez-García and Wynne (2010) and Kabukçuoğlu and Martínez-García (2016b) who demonstrate theoretically that an open-economy Phillips curve constitutes an efficient forecasting framework for inflation forecasting of open economies. These authors warn, however, that the absence of reliable global slack measures poses a challenge to accurately forecast inflation and suggest using indirect measures of economic activity slack instead (an approach that has gained particular importance since then).

New Zealand's cross-country linkages can be incorporated into an open-economy Phillips curve-based model for inflation forecasting by either (i) directly modelling the linkages through global slack exploiting all available international evidence in the construction of such a measure or (ii) indirectly through some reliable indicators of the tone of global economic slack, such as oil prices or global inflation. We construct both direct and indirect global measures of economic activity using macroeconomic data from New Zealand and rest of the world economies (in particular, we employ measures of global slack, global inflation, and oil prices) in order to evaluate empirically the extent to which global forces help forecast domestic inflation beyond what historical data on inflation tells us.

Our empirical approach is related to that of Kabukçuoğlu and Martínez-García (2016b) who studied 14 advanced countries since the 1980s (at the onset of the Great Moderation period). In line with the existing literature, we assess the forecasting performance of various specifications of the open-economy New Keynesian Phillips curve model relative to a naïve forecasting model for New Zealand. To be more precise, we conduct pseudo out-of-sample forecasts for two inflation measures-headline CPI and core CPI (all items ex. food and energy)at horizons varying between 1-quarter to 12-quarters ahead. Our benchmark estimation and forecast periods are 1980:Q3-1996:Q4 and 1997:Q1-2015:Q1, respectively. ${ }^{4}$

In any of our forecasting model specifications, the goal is to understand how taking into account foreign economic activity and spatial effects in the global macroeconomy contributes to forecasting accuracy. We evaluate the following specifications:

- An autoregressive (AR) process of New Zealand inflation (our naïve benchmark).

- An open-economy New Keynesian Phillips curve, based on an autoregressive distributed lag (ADL) model of New Zealand inflation and West Texas Intermediate (WTI) oil prices.

- An open-economy New Keynesian Phillips curve, based on an ADL model of inflation and global slack constructed using either gross domestic product (GDP) or industrial production (IP) data.

of the RBNZ shall be to deliver 'stability in the general level of prices.' The Act also says that the Minister of Finance and the RBNZ's Governor shall together have a separate agreement setting out specific targets for achieving and maintaining price stability (known as the Policy Targets Agreement, PTA). For more details, see:

http://www.bankofengland.co.uk/education/Documents/ccbs/handbooks/pdf/ccbshb29.pdf

${ }^{4}$ The sample period 1980:Q1-2015:Q1 on New Zealand data covers inflation targeting since its adoption at the end of 1989 as well as the period immediately before which led to it. 
- An ADL model of New Zealand and rest of the world inflation, albeit this specification only partly captures the information content in global slack (as noted in Kabukçuoğlu and Martínez-García (2016b)).

- An open-economy New Keynesian Phillips curve, based on an ADL model of New Zealand inflation with rest of the world inflation and WTI oil price data.

Our metric for forecast accuracy is the mean squared forecast error (MSFE) of a given model against that of the AR benchmark model. We follow Clark and McCracken (2005) and Kabukçuoğlu and Martínez-García (2016a) to calculate the critical values for the F-test statistic that we use for testing the null of no improvement in forecasting accuracy over what the AR benchmark achieves. Our empirical analysis suggests that New Zealand inflation exhibits similar patterns to those of other advanced countries and that an open-economy Phillips curve helps explain the country's inflation dynamics under the inflation targeting regime.

Globalization does not render the central bank powerless, as the New Zealand experience shows. The central bank has the tools to counter risks to price stability and anchor inflation expectations - and the inflation targeting regime provides a viable policy framework to do so. However, the fact that we can find statistically significant evidence that domestic inflation is influenced to some extent by global factors for New Zealand-operating under a wellestablished, credible inflation targeting regime for more than 25 years-is very significant. It illustrates how the forces of globalization are still felt underneath such a potent monetary policy framework (inflation targeting) and how global factors are indeed some of the key risks to price stability that central banks must contend with (and understand) in their policymaking decisions.

The reminder of the introduction provides a more detailed literature review to better place the contribution of our paper in the context of the existing literature. In section 2, we theoretically motivate our empirical strategy and present the main empirical results of our analysis. In section 3 , we briefly conclude.

Related literature. The standard (closed-economy) Phillips curve has played a major role in macroeconomic research-for monetary policy and on the formation of public and private expectations about future inflation. However, an important strand of the literature that began with Atkeson and Ohanian (2001) documented the declining forecasting accuracy of Phillips curve-based U.S. inflation models during the Great Moderation period and has put into question the significance of the Phillips curve relationship itself. The evidence suggests that closedeconomy forecasts under the Phillips curve specification have become less accurate relative to those obtained from naïve specifications judging by conventional performance metrics such as the mean squared forecasting error (MSFE). An extensive survey by Stock and Watson (2008) suggests that Phillips curve-based forecasts of U.S. inflation, as well as related forecasts that add also other conventional domestic explanatory macro variables, produce accurate forecasts only occasionally.

The low success in forecasting U.S. inflation has not only been derived under reducedform forecasting specifications based on the Phillips curve relationship, but also from a more structural approach (e.g., Edge and Gürkaynak (2010)). Kabukçuoğlu and Martínez-García $(2016 a, b)$ provide further empirical evidence on the weak performance of closed-economy Phillips curve relative to an autoregressive process for a large number of advanced economies besides the U.S. Binyamini and Razin (2007) and Martínez-García and Wynne (2010) provide theoretical support for the global slack hypothesis and Borio and Filardo (2007) show empirical evidence for it. Duncan and Martínez-García (2015) and Kabukçuoğlu and Martínez-García 
$(2016 a, b)$ find broad support for the open-economy Phillips curve which is shown to be more consistent with the data than the traditional closed-economy relationship judging by their forecasting accuracy. In this study, we provide empirical evidence indicating that New Zealand (even under an inflation targeting regime) is no exception in that regard.

However, other papers find more mixed evidence on the empirical merits of the global slack hypothesis. For instance, Ball (2006), Ihrig, Kamin, Lindner, and Marquez (2010), Pain, Koske and Sollie (2006), and Milani $(2010,2012)$ find at best weak empirical evidence for the global slack hypothesis. We argue that it is important to note that these studies base their analysis largely on conventional (mostly statistical) measures of global slack, whose measurement can be challenging and noisy in practice. Hence the inconclusive evidence on the global slack hypothesis may primarily be an issue arising from inaccurate measures of global slack-which does not necessarily invalidate in our view the global slack hypothesis (in particular, the open-economy Phillips curve relationship).

The findings of Kabukçuoğlu and Martínez-García $(2016 a, b)$ indicate that measures of global economic activity may be inaccurate and unreliable since it is difficult to estimate the potential output in general and because data availability (and even its quality) can vary greatly across countries. In turn, other theoretically-consistent indirect measures that proxy for global slack-such as U.S. real effective exchange rates, terms of trade, global inflation, G7 money supply growth, and G7 private credit growth-outperform the naïve forecasting model (the benchmark AR model) as well as forecasts based on the closed-economy Phillips curve which employ domestic slack measures only.

Kabukçuoğlu and Martínez-García (2016b), in particular, propose replacing the hard-tomeasure global slack with: (i) global inflation and domestic slack or (ii) global inflation and the terms of trade gap. ${ }^{5}$ Our forecasting strategy in this paper follows here the work of Kabukçuoğlu and Martínez-García (2016b) whereby oil prices movements proxy for the terms of trade gap in (ii). Hence, our preferred inflation forecasting model is based on the open-economy Phillips curve specification that uses global inflation and oil price movements Our empirical analysis reveals that among these two variables, global inflation potentially has a greater information content for domestic inflation. However, it is important to point out that global inflation alone does not suffice to efficiently forecast inflation according to theory (that is, according to the workhorse New Keynesian model), as argued in Kabukçuoğlu and Martínez-García (2016b). In this regard, our empirical evidence shows that oil price movements appear to help indeedparticularly for New Zealand's core inflation.

\section{Empirical Analysis}

\subsection{Data}

In order to construct global inflation and global slack series, we use data from the Federal Reserve Bank of Dallas' Database of Global Economic Indicators (DGEI) (see the details about this dataset in Grossman, Mack and Martínez-García (2014)). Our analysis is based on

\footnotetext{
${ }^{5}$ Alternatively, Duncan and Martínez-García (2015) propose a multiple-equation Bayesian VAR (BVAR) forecasting model based on the open-economy New Keynesian model solution to incorporate the output and inflation linkages with the rest of the world.
} 
quarterly time series and covers the period of 1980:Q3 to 2015:Q1. All series are seasonally adjusted.

The inflation rate is calculated with annualized log-differences of the quarterly series of two price indexes, the headline consumer price index (CPI) and the core CPI (i.e., CPI excluding food and energy). Aggregate rest of the world inflation series are constructed by equal weighting of the inflation series of a sample of countries listed in the Appendix. ${ }^{6}$ (Country coverage for the aggregates varies with data availability over our sample period.)

The global slack measures are based on the weighted averages of detrended industrial production (IP) and GDP data. We consider an equal weighting scheme in the aggregation of slack measures as well. For detrending the country-level IP and GDP series, we use either firstdifferencing or the one-sided HP filter described in Stock and Watson (1999b). Our implementation of the one-sided HP filter here is based on the Kalman approach.

The oil price series is West Texas Intermediate (WTI) Crude Oil (40 deg.), obtained from Haver Analytics. We use nominal series and compute filtered oil prices with either firstdifferencing or the one-sided HP filter. ${ }^{7}$ See Figures 1 and 2 in the Appendix for an illustration of all the data employed in our subsequent forecasting exercise.

\subsection{Modelling Inflation Under Inflation Targeting}

We are motivated by the theoretical basis of the workhorse New Keynesian model built by Martínez-García and Wynne (2010) and Kabukçuoğlu and Martínez-García (2016a,b). A simple extension of the workhorse New Keynesian model of Martínez-García and Wynne (2010) can be cast in the following hybrid open-economy Phillips curve form

$$
\pi_{\mathrm{t}}=\bar{\alpha} E_{t}\left(\pi_{\mathrm{t}+1}\right)+\bar{b} \pi_{\mathrm{t}-1}+\bar{c} \mathrm{y}_{\mathrm{t}}+\mathrm{u}_{\mathrm{t}}
$$

featuring both backward-looking as well as forward-looking terms. Here, $\pi_{t}$ is the inflation rate, $E_{t}\left(\pi_{\mathrm{t}+1}\right)$ is the expected inflation rate, and $\mathrm{y}_{\mathrm{t}}$ refers to the real marginal costs associated to the production of the domestic basket of local goods and imports. This notion of real marginal costs is tied in the workhorse New Keynesian model to global slack or alternatively to a vector of indicators that proxies for global slack (including, e.g., global inflation, oil prices). The error term $u_{t}$ captures all exogenous innovations to the hybrid open-economy Phillips curve.

The first-order differential equation in (1) introduces dynamic lags in the transmission arising from modelling price indexation à la Yun (1996) into an otherwise standard Calvo (1983)type model of price setting behavior. We can allow for longer lags in price indexation and introduce additional features that give a role to lagged real marginal costs as well. Hence, we simply generalize the hybrid open-economy Phillips curve in (1) as follows

\footnotetext{
${ }^{6}$ D'Agostino and Surico (2009), among others, suggest that equal weighting generally yields among the best forecasting outcomes across different forecasting specifications when the exact weights are otherwise uncertain.

7 The movements of nominal WTI crude oil price proxy for the terms of trade gap in Kabukçuoğlu and Martínez-García (2016b). However, oil price movements also reflect the global forces driving commodities markets and global inflation more broadly which can help us forecast inflation better as well.
} 


$$
\pi_{\mathrm{t}}=\sum_{s=1}^{m} \bar{\alpha}_{s} E_{t}\left(\pi_{\mathrm{t}+\mathrm{s}}\right)+\sum_{s=1}^{p} \bar{b}_{s} \pi_{\mathrm{t}-\mathrm{s}}+\sum_{s=1}^{q} \bar{c}_{s} \mathrm{y}_{\mathrm{t}-\mathrm{s}}+\mathrm{u}_{\mathrm{t}}
$$

to better capture all relevant dynamics that may affect the dynamics of inflation in the data (with up to $p$ and $q$ lags and $m$ leads).

Under an inflation targeting regime, the rational expectations equilibrium of the workhorse New Keynesian model implies that inflation expectations must be exactly anchored by the inflation target-possibly a constant - set by the central bank so long as this is a credible target (see Kabukçuoğlu and Martínez-García (2016b) on this point). Then, the generalized openeconomy Phillips curve in (2) under well-anchored inflation expectations can be written as

$$
\pi_{\mathrm{t}}=\bar{a}+\sum_{s=1}^{p} \bar{b}_{s} \pi_{\mathrm{t}-\mathrm{s}}+\sum_{s=1}^{q} \bar{c}_{s} \mathrm{y}_{\mathrm{t}-\mathrm{s}}+\mathrm{u}_{\mathrm{t}}
$$

where $\pi^{T}$ is the constant inflation target, and $\bar{a} \stackrel{\text { def }}{=} \pi^{T} \sum_{s=1}^{m} \bar{\alpha}_{s}$ is the intercept in (3). Here, in equilibrium must hold that $E_{t}\left(\pi_{\mathrm{t}+\mathrm{s}}\right)=\pi^{T}$ for all $\mathrm{s}=1, \ldots, \mathrm{m}$. This expression captures the relevant structural relationship underpinning the inflation dynamics of the model that we investigate in our subsequent empirical analysis.

We rely on the assumption that the central bank adheres to an inflation targeting framework that helps tightly anchor inflation expectations. In this regard, the experience of New Zealand is rather significant for us precisely because of its long adherence to inflation targeting and the remarkable success achieved anchoring inflation expectations (Figure 3). Inflation expectations have remained close to the upper bound of the inflation targeting range set jointly by the Reserve Bank of New Zealand and the Ministry of Finance. Moreover, the upper bound has remained invariant since the mid-1990s (coinciding with the forecasting sample period we use for our empirical analysis) as implied by the generalized relationship in (3). ${ }^{8}$

\subsection{Empirical Models for Forecasting Inflation}

For a given quarterly forecast horizon $\mathrm{h}$ ranging from 1-quarter ahead to 12-quarters ahead, we denote an inflation forecast h-quarters ahead that uses all information up to quarter $\mathrm{t}$ as $\pi_{\mathrm{t}+\mathrm{h} \mid \mathrm{t}}$. We define the $\mathrm{h}$-quarter ahead (annualized) inflation as $\pi_{\mathrm{t}+\mathrm{h} \mid \mathrm{t}}=\frac{400}{\mathrm{~h}} \times \ln \left(\frac{\mathrm{p}_{\mathrm{t}+\mathrm{h}}}{\mathrm{p}_{\mathrm{t}}}\right)$. For our forecast evaluation exercise, we consider the following competing model specifications in Autoregressive Distributed Lag (ADL) form: ${ }^{9}$

First, we introduce our baseline autoregressive (AR) model to predict inflation (with no spatial dimension), i.e.,

\footnotetext{
${ }^{8}$ The dynamics of the generalized inflation process in equation (3) reflect transmission lags, but potentially also capture the transition path whereby inflation expectations become anchored around the target-a transition that occurred over time in the 1980s leading to the adoption of inflation targeting in New Zealand, as suggested by the survey-based evidence shown in Figure 3. Notice that survey-based inflation expectations became largely stable around $2.5 \%$ quickly after the implementation of inflation targeting in New Zealand at the end of 1989.

${ }^{9}$ The ADL specification is a convenient statistical framework as it enables us to use the well-established techniques for estimation, inference, and forecasting.
} 


$$
\pi_{\mathrm{t}+\mathrm{h} \mid \mathrm{t}}=a_{1}+\sum_{s=1}^{p} b_{1, s} \pi_{\mathrm{t}-\mathrm{s}}+u_{1, t+h} \quad(\text { Model } 1)
$$

which forecasts future inflation using the past inflation rates $\pi_{t}$ alone and defines our naïve forecasting model. The optimal number of lags is selected based on the Schwarz Information Criterion (SIC). To keep the model parsimonious and since we use quarterly series, we let the maximum number of possible lags $p$ to be equal to four. Model 1 serves as the benchmark against which we compare the accuracy of our remaining open-economy Phillips curve-based models.

Second, Model 2 emerges from the (generalized) open-economy Phillips curve under inflation targeting given in (3) above,

$$
\left.\pi_{\mathrm{t}+\mathrm{h} \mid \mathrm{t}}=a_{2}+\sum_{s=1}^{p} b_{2, \mathrm{~s}} \pi_{\mathrm{t}-\mathrm{s}}+\sum_{s=1}^{q} c_{2, s} \mathrm{y}_{\mathrm{t}-\mathrm{s}}+u_{2, t+h} \quad \text { (Model } 2\right)
$$

In this specification, we use the distributed lag of earlier inflation rates, $\pi_{t}$, and global slack, $y_{t}$, in order to forecast $h$-quarters ahead inflation, $\pi_{t+h \mid t}$. The distributed lag of earlier inflation rates, $\pi_{t}$, proxies for lags in the transmission (and transitional dynamics) while the intercept captures the notion of well-anchored expectations implied by a credible and stable inflation target in equilibrium.

Taking $\mathrm{p}$ as given from Model 1 , the lag length selection for $\mathrm{q}$ is based on the SIC criteria and its maximum lag length is set at four. Notice that this specification is also referred to as an economic model, as broadly defined by Stock and Watson (2003) (see also Stock and Watson (1999a), Stock and Watson (1999b), Stock and Watson (2008)), since the model uses explanatory variables in a specification based on the open-economy Phillips-curve.

Global slack can be defined as the equally-weighted aggregate of domestic and foreign slack measures based on country-level GDP or IP data. With these explanatory variables, we directly take into account the role of foreign economic activity along with that of domestic measures. This specification is also used in order to test the forecasting accuracy of the WTI oil price series. In this case, it enables us to evaluate the role of global economic activity in domestic inflation determination indirectly. In theory, this specification is reminiscent of an openeconomy Phillips curve where global slack is proxied by oil price movements (Kabukçuoğlu and Martínez-García (2016b)).

Third, Model 3 evaluates the predictive accuracy of global inflation alone. In doing so, we consider a model of domestic inflation based on global inflation in the spirit of Kabukçuoğlu and Martínez-García (2016b). More specifically, this is a variant of the ADL model implied by (3) that constitutes the key forecasting framework we use to investigate not just the effect of global interdependencies on domestic inflation, but also the spatial and temporal dimensions that affect the determination of inflation. Model 3 can be written as follows,

$$
\pi_{\mathrm{t}+\mathrm{h} \mid \mathrm{t}}=a_{3, s}+\sum_{s=1}^{p} b_{3, s} \pi_{\mathrm{t}-\mathrm{s}}+\sum_{s=1}^{q} d_{3, s} \pi_{\mathrm{t}-\mathrm{s}}^{*}+u_{3, t+h} \text { (Model 3) }
$$

On the right-hand side, we introduce the distributed lags of rest of the world inflation, $\pi_{t-s}^{*}$. Rest of the world inflation is constructed based on the equal weighting of the inflation series of 
the countries in our sample (see the Appendix for details). Again, taking $p$ as given from Model 1 , the maximum lag length $q$ is set at four and chosen optimally with the SIC criteria.

Model 3 can be particularly helpful in cases where data availability and quality problems for slack measures create a challenge for forecasting inflation accurately under an openeconomy Phillips curve-based specification. However, Model 3 incorporates only partially the channels that explain the dynamics of domestic inflation and their relation to global inflation found in the workhorse New Keynesian model. As discussed in Kabukçuoğlu and Martínez-García (2016b), an efficient and theoretically-consistent forecast would require us to use: (i) global inflation and domestic slack or (ii) global inflation and the terms of trade gap proxied with oil price movements.

Forth, we adopt Model 4 to explicitly capture all spatial linkages in both inflation and economic activity (not only those summarized by global inflation alone in Model 3 ) following the specification proposed by Kabukçuoğlu and Martínez-García (2016b),

$$
\left.\pi_{\mathrm{t}+\mathrm{h} \mid \mathrm{t}}=a_{4, s}+\sum_{s=1}^{p} b_{4, s} \pi_{\mathrm{t}-\mathrm{s}}+\sum_{s=1}^{q} c_{4, s} \pi_{\mathrm{t}-\mathrm{s}}^{*}+\sum_{s=1}^{q} d_{4, s} \mathrm{y}_{\mathrm{t}-\mathrm{s}}+u_{4, t+h} \quad \text { (Model } 4\right)
$$

In order to circumvent measurement issues with domestic slack, we adopt the variant in Kabukçuoğlu and Martínez-García (2016b) which uses global inflation and oil price movements rather than global inflation and domestic slack. In Model 4, therefore, we simply use foreign inflation and oil price movements in order to investigate the role of global economic activity on domestic inflation under the open-economy Phillips curve model. Again, the optimal lag length selection takes $p$ as given from Model 1 and chooses $q$ based on the SIC criteria allowing a maximum of up to four lags.

Finally, it is important to note here that we determine the lag length on inflation $p$ only once in Model 1 based on the SIC criteria. Then we take the lag length p from Model 1 as given, and determine the lag length of the additional variable(s) $q$ in the corresponding extended economic model (Model 2, 3, and 4) based on the SIC criteria. Consequently, any of the alternative specifications (Model 2, 3, and 4) becomes nested with Model 1 which simplifies (and facilitates) the forecasting performance comparisons.

\subsection{Forecasting Scheme and Metric for Forecast Accuracy}

We perform forecasts based on the pseudo out-of-sample forecasting method. We focus on recursive samples, i.e. at any given date $t$, we forecast inflation at date $t+h$ using all available data up to date t. All models can be estimated by OLS. We assess the multi-step pseudo out-ofsample forecasting performance of Model 2, 3, and 4 relative to the forecast of a univariate autoregressive (AR) process (Model 1).

Our forecast evaluation metric, the relative mean squared forecasting error (MSFE), can be defined as the ratio of the MSFE of the extended economic model (Model 2, Model 3 or Model 4) relative to that of the benchmark AR model (Model 1). Let 0 denote the starting date of the data and $T$ denote the end date. The estimation sample starts at 0 and ends in $t_{0}$. We start using all data up to date $t_{0}$ to forecast inflation at date $t_{0}+h$. By adding one additional observation each time to the estimation sample, we are estimating the parameters of interest of the model recursively and the forecasts $h$-periods ahead as well. 
The $h$-step recursive forecast continues until period $T-h$ with a total of $T-h-t_{0}+1$ steps. For any of our models, i.e. for $i=1, \ldots, 4$, this procedure yields a sequence of forecast errors, $\left\{\hat{u}_{i, t+h}\right\}_{\mathrm{t}=\mathrm{t}_{0}}^{\mathrm{T}-\mathrm{h}}$, which helps us construct the MSFE of Model $\mathrm{i}$ at horizon $\mathrm{h}$ from date $\mathrm{t}_{0}$ to $\mathrm{T}-\mathrm{h}$ as follows

$$
\operatorname{MSFE}_{i}^{h}=\frac{1}{\mathrm{~T}-\mathrm{h}-\mathrm{t}_{0}+1} \sum_{\mathrm{t}=\mathrm{t}_{0}}^{\mathrm{T}-\mathrm{h}} \hat{u}_{i, t+h}^{2}
$$

If the relative MSFE is greater than 1 , this implies that the naïve forecast (Model 1 ) is more accurate than the alternative economic model (Model 2, 3 or 4).

In our benchmark experiments where we forecast headline CPI and core CPI inflation under the four models described before, the estimation sample begins in 1980:Q1 and ends in 1997:Q3 and the pseudo out-of-sample forecasting period begins in 1997:Q4 and ends in 2015:Q1 leaving us with an initial estimation sample of 71 quarters and a pseudo out-of-sample forecasting sample of 70 quarters.

\subsection{Hypothesis Testing}

For inference in nested models such as Model 1 versus Model 2 or Model 3 (both of which incorporate only one additional explanatory variable), an appropriate methodology for testing the statistical significance of the relative MSFEs is described by Clark and McCracken (2006). These authors suggest a bootstrap algorithm to calculate the critical values for the Fstatistics needed for hypothesis testing. Kabukçuoğlu and Martínez-García (2016a) extend the Clark and McCracken (2006) methodology further to compare the performance with more than one additional explanatory variable distinguishing two nested models (that is the relevant case for comparing Model 1 vs. Model 4).

The procedure of Clark and McCracken (2006) and Kabukçuoğlu and Martínez-García (2016a) involves resampling from the residuals of vector autoregressive (VAR) equations. In order to test the predictive ability of a single variable forecast as in Model 1, we define an equation for inflation (as governed by the restricted Model 1 ) and an equation for the predicting variable(s) (e.g. oil prices, global slack, global inflation, global inflation and oil prices), where the lag length for the predicting variable(s) and inflation are separately determined based on the SIC criteria. The equations of the data generating process (DGP) are estimated by OLS with a number of bootstrap iterations equal to 5000 .

We then compute a one-sided test under the null hypothesis that the extended economic model (Model 2, 3, 4) does not yield more accurate forecasts than the benchmark AR process (Model 1), i.e. $M S F E_{h, 1} \leq M S F E_{h, i}, \mathrm{i}=2,3,4$ at a forecast horizon $\mathrm{h}=1,2, \ldots, 12$. Throughout the paper, we report the MSFE of the benchmark AR model and the relative MSFEs of a particular economic model (Model 2, 3 or 4) relative to the benchmark (Model 1). The null hypothesis is expressed as 'the relative MSFE is greater than or equal to 1.' We report the $p$ values of the F-test at conventional statistical levels of $1 \%, 5 \%$, and $10 \%$. 


\subsection{Main Empirical Findings}

Our results are reported in Tables $1 \mathrm{~A}-1 \mathrm{~B}$, Table 2, Tables $3 \mathrm{~A}-3 \mathrm{~B}$, and summarized in Figure 4 in the Appendix. In Tables 1A-1B panel (a), we report the absolute MSFE of the forecasts of headline CPI and core CPI inflation for New Zealand under the AR benchmark (Model 1), respectively. All remaining entries in these tables report relative MSFEs for Models 2-4 vs. Model 1. We report results for forecast performance $1,4,6,8,10$, and 12 quarters ahead.

In Table 1A, the forecasts based on Model 2 with one-sided HP-filtered (HP1) WTI oil prices appear to be more accurate than the benchmark AR process at longer horizons $(8,10$ and 12). No other measure of economic activity (first-differenced oil series, IP or GDP-based slack measures) can outperform the AR benchmark. These results do not necessarily invalidate the global slack hypothesis for New Zealand, but may simply reflect that the slack measures may be poorly measured.

We consider a similar exercise with core CPI inflation (i.e. CPI excluding food and energy). The results are reported in Table 1B. ${ }^{10}$ Again, global slack measures based on IP and GDP do not provide more accurate forecasts than the naïve specification. Oil prices, which is less likely to provide information content for core $\mathrm{CPI}$, do not appear to be helpful for forecasting in this case either.

Next, we consider Model 3 (see Table 2) where we take into account spatial interlinkages by using aggregate rest of the world inflation as a predictor. As reported in Table 2 and seen in Figure 4, this specification of domestic inflation based on global inflation yields more accurate forecasts than the simple AR model. Moreover, these results are highly robust to both inflation measures (headline and core) and across forecast horizons. Even though Model 3 does not provide a prescription for an efficient forecast, it can be seen as a reliable forecasting model for inflation dynamics in an open economy like New Zealand.

One possible interpretation of this result would be as follows: An aggregation of the rest of the world economies' inflation series provides a more accurate reading-albeit an indirect one-of global economic activity than currently available measures of global slack. Moreover, this result reinforces in our view the idea that global economic activity influences domestic inflation for New Zealand (as it does for other countries, according to what the related literature suggests). Although here imperfect measures of economic activity (in particular, global slack) make it harder to otherwise detect the role that global factors are actually playing in domestic inflation.

Next, we examine the forecast accuracy of global inflation together with oil prices (based on a one-sided HP filter and first differencing) under Model 4 relative to the benchmark (Model 1). As can be seen in the results reported in Table 3A, one-sided HP-filtered oil prices with global inflation help forecast domestic headline inflation only occasionally-at 6 or 8 quarters ahead. First-differenced oil series, on the other hand, do not have a significant information content for headline inflation.

\footnotetext{
${ }^{10}$ In a preliminary assessment, we also considered Model 2 for forecasts under a closed-economy Phillips curve, using GDP and IP series to construct measures of domestic slack. This specification is usually weak for forecasting and outperforms the AR process of inflation only rarely, a result that is in line with the findings in Kabukçuoğlu and Martínez-García $(2016 a, b)$ across many advanced economies.
} 
Finally, the results reported in Table 3B suggest that Model 4 can be a good framework for forecasting domestic core inflation (instead of headline). In fact, oil prices and global inflation help forecast domestic core inflation more accurately than the benchmark AR (Model 1). Moreover, as seen in Figure 4, these results are comparable to and often better than those obtained under Model 3 (which only uses global inflation) whenever the detrending of the oil price series is based on a one-sided HP filter.

We argue here that, consistent with the theory laid out in Kabukçuoğlu and MartínezGarcía (2016b), a flatter open-economy Phillips curve may result in domestic inflation being largely dominated by global inflation. This appears to be the case for New Zealand as well since we find most of the improvement in forecasting accuracy can be attributed to global inflation anyway. Nonetheless, we conclude that taking into account the spatial interlinkages fully, it is possible to generate more accurate forecasts of inflation-and not just for headline but particularly for core-under inflation targeting (as it is the case for New Zealand). ${ }^{11}$

\section{Concluding Remarks}

The seminal work of Atkeson and Ohanian (2001) documented a break in the (closedeconomy) Phillips curve during the Great Moderation period in the U.S. This basic statistical relationship between domestic inflation and domestic economic activity no longer seemed to work as a tool for inflation forecasting. Kabukçuoğlu and Martínez-García $(2016 a, b)$ argued that the result is ubiquitous across many advanced economies, but that an open-economy Phillips curve can capture domestic inflation dynamics more accurately. The Phillips curve is alive and well-albeit in its open-economy form!

Our study shows that New Zealand, operating under a long-standing inflation targeting regime, is no different. Indeed, we empirically show that the open-economy Phillips curve for New Zealand is a valid specification-so long as one considers an open-economy Phillips curve specification based on global inflation and oil price movements meant to overcome some of the limitations associated with the existing measures of global slack. We ultimately find that incorporating the spatial dimension of the international linkages of New Zealand's economy is important to improve the forecasting accuracy of the open-economy Phillips curve model.

Given the strength of open-economy Phillips curve specifications to explain the inflation dynamics across so many different economies relative to the current benchmark (i.e. the autoregressive model), we would also argue that the open-economy Phillips model may be a more appropriate benchmark for forecast evaluation going forward. Even a simple global inflation model would introduce a higher yardstick for inflation forecasting models.

In conclusion, our study adds further evidence to the empirical literature and suggests that globalization affected inflation dynamics in New Zealand. Our preferred variables reflecting economic activity slack (global inflation and oil price movements) offer empirical support consistent with the existence of a non-trivial trade-off between domestic inflation and global slack as described by the open-economy Phillips curve (which holds across different monetary policy regimes including for the inflation targeting that we study here for New Zealand).

\footnotetext{
${ }^{11}$ An interesting path of future analysis could be to consider alternative proxies for global slack for New Zealand (global money supply growth, global credit growth, real effective exchange rate, and the terms of trade, as shown in Kabukçuoğlu and Martínez-García (2016a)). We leave that for future research.
} 


\section{Appendix}

\section{A1. Figures}
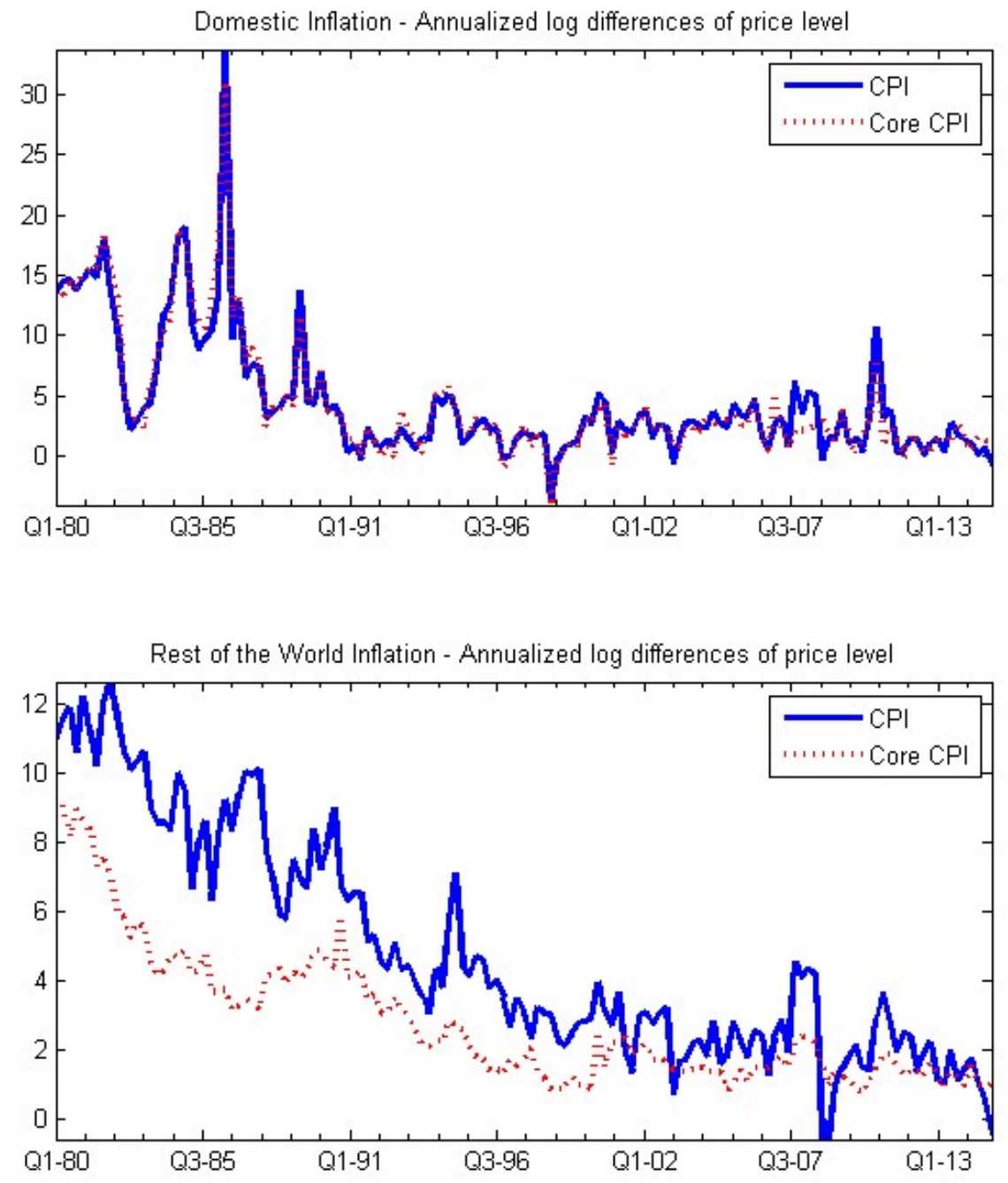

Figure 1: Domestic inflation and aggregate rest of the world inflation measures (in percentages) 
Global slack (FD) - equally-weighted slack measures
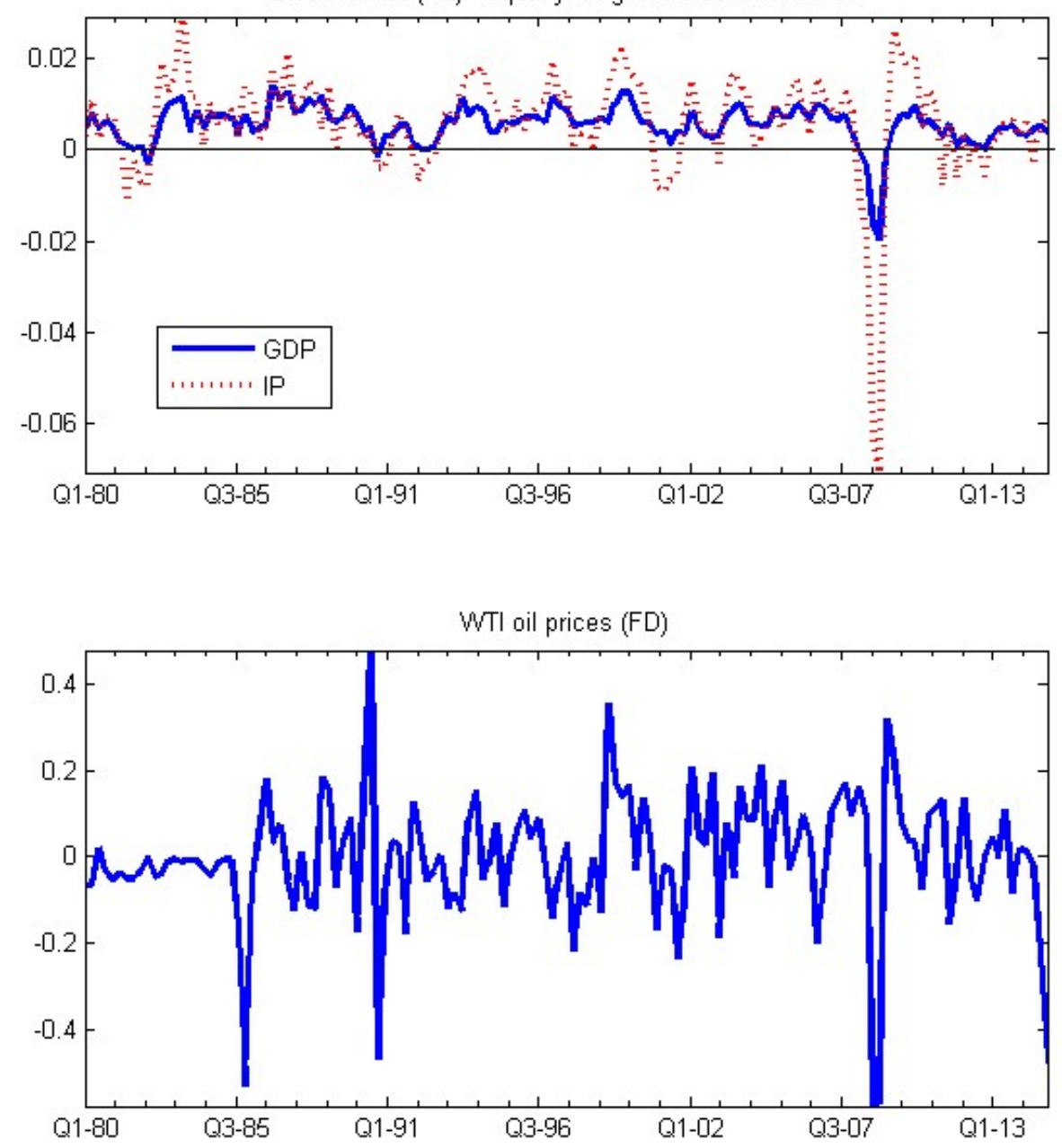

Figure 2: Global slack and oil price series 
Inflation Expectations and Target

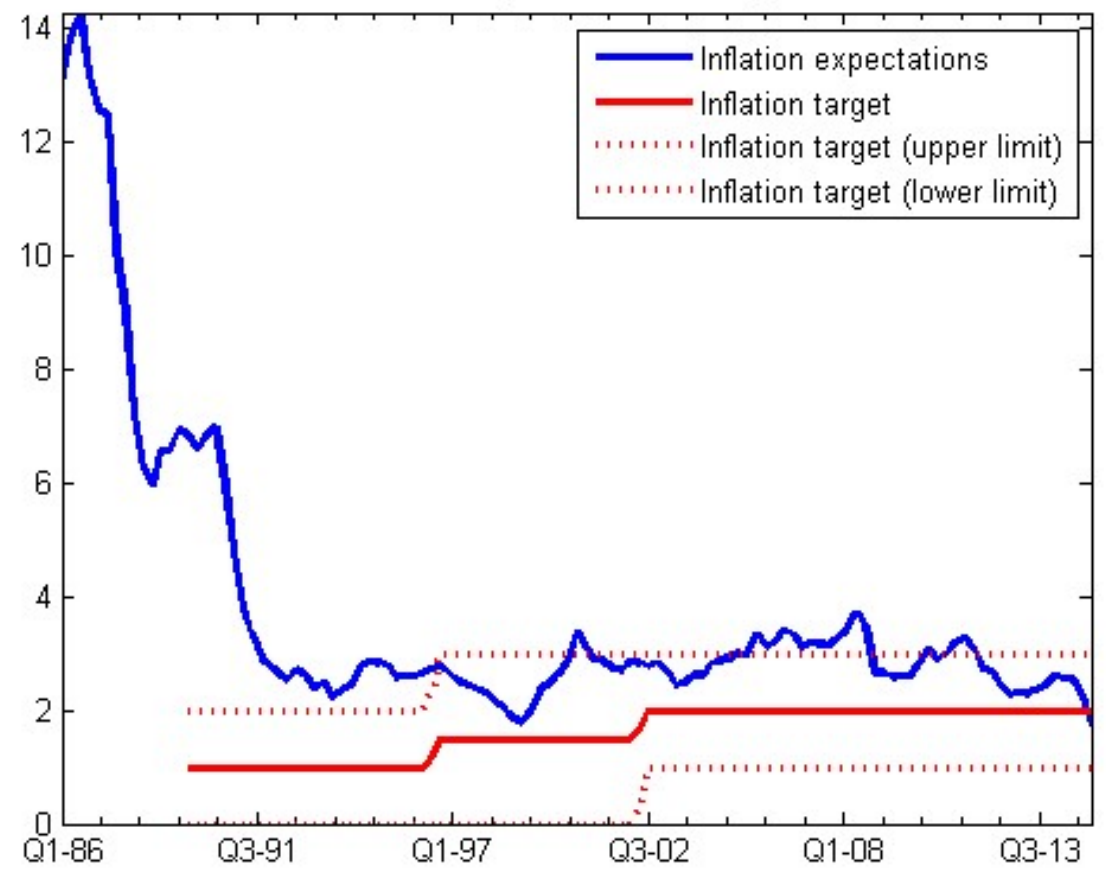

Figure 3: New Zealand inflation expectations (all sectors) and inflation target (in percentages). Source: Business Outlook Survey - ANZ National Bank and National Bank of New Zealand; Reserve Bank of New Zealand

$\square \mathrm{h}=1 \quad \square \mathrm{h}=4 \quad \square \mathrm{h}=6 \quad \square \mathrm{h}=8 \quad \square \mathrm{h}=10 \quad \square \mathrm{h}=12$

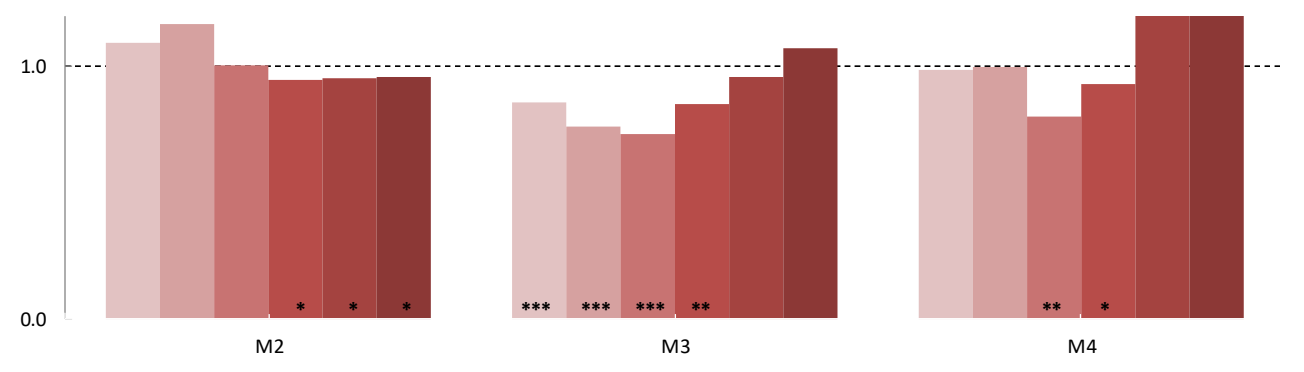

$\square \mathrm{h}=1 \quad \mathrm{~h}=4 \quad \square \mathrm{h}=6 \quad \square \mathrm{h}=8 \quad \square \mathrm{h}=10 \quad \square \mathrm{h}=12$

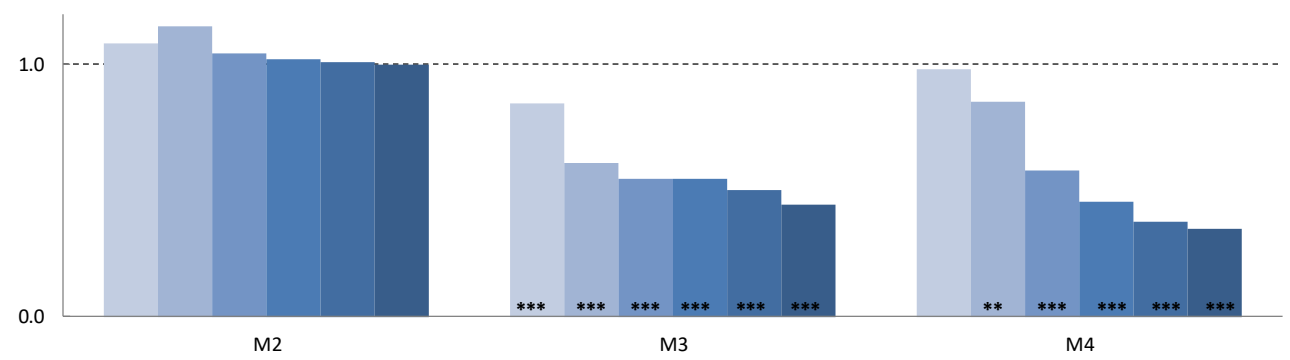

Note: The figure plots the best variant of each model at each forecasting horizon as reported in Tables 1A, 1B, 2, 3A, and 3B. Except for Model 2 with core inflation at $h=1$ where the global GDP variant dominates, all other variants of Model 2 and Model 4 are dominated by WTI oil prices (one-sided HP filtered). P-value indicates statistical significance at $10 \%(*), 5 \%(* *)$, or $1 \%(* * *)$.

Figure 4: Ratio of MSFE of the economic models (Model 2, 3, and 4) relative to the benchmark (Model 1) 


\section{A2. Tables}

\begin{tabular}{|c|c|c|c|c|c|c|}
\hline \multicolumn{7}{|c|}{ Table 1A. Forecasts of CPI inflation - Relative MSFEs (1997Q3:2015Q1) } \\
\hline Horizon & 1 & 4 & 6 & 8 & 10 & 12 \\
\hline Model 1 & (a) & & & & & \\
\hline Autoregressive & 4.857 & 3.433 & 2.904 & 2.541 & 2.045 & 1.861 \\
\hline \multicolumn{7}{|l|}{ Model 2} \\
\hline & (b) & & & & & \\
\hline Global slack (IP) & 1.197 & 1.83 & 2.25 & 2.403 & 2.480 & 2.334 \\
\hline \multirow[t]{2}{*}{ Global slack (GDP) } & 1.097 & 1.557 & 1.846 & 1.832 & 1.707 & 1.530 \\
\hline & (c) & & & & & \\
\hline WTI oil price HP1 & 1.092 & 1.17 & 1.007 & $0.945^{*}$ & $0.951 *$ & $0.959 *$ \\
\hline WTI oil price FD & 1.253 & 1.391 & 1.35 & 1.122 & 1.055 & 1.084 \\
\hline
\end{tabular}

\begin{tabular}{|c|c|c|c|c|c|c|}
\hline Horizon & 1 & 4 & 6 & 8 & 10 & 12 \\
\hline Model 1 & (a) & & & & & \\
\hline Autoregressive & 4.026 & 2.952 & 2.903 & 2.761 & 2.476 & 2.422 \\
\hline \multicolumn{7}{|l|}{ Model 2} \\
\hline & (b) & & & & & \\
\hline Global slack (IP) & 1.144 & 1.793 & 2.132 & 2.276 & 2.322 & 2.233 \\
\hline Global slack (GDP) & $\begin{array}{l}1.085 \\
\text { (c) }\end{array}$ & 1.551 & 1.779 & 1.780 & 1.730 & 1.628 \\
\hline WTI oil price HP1 & 1.103 & 1.153 & 1.044 & 1.02 & 1.011 & 0.999 \\
\hline WTI oil price FD & 1.21 & 1.356 & 1.263 & 1.104 & 1.054 & 1.045 \\
\hline
\end{tabular}




\begin{tabular}{|c|c|c|c|c|c|c|}
\hline Horizon & CPI 1 & 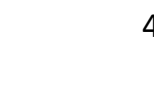 & $\epsilon$ & 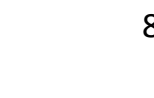 & 10 & 12 \\
\hline \multicolumn{6}{|l|}{ Model 3} & \\
\hline Global inflation & $0.855^{* * *}$ & $0.760 * * *$ & $0.733^{* * *}$ & $0.852^{* *}$ & 0.958 & 1.074 \\
\hline Model 3 & $\begin{array}{l}\text { Core CPI } \\
\text { (b) }\end{array}$ & & & & & \\
\hline Global inflation & $0.844^{* * *}$ & $0.609 * * *$ & $0.549 * * *$ & $0.548 * * *$ & $0.504^{* * *}$ & $0.448 * * *$ \\
\hline
\end{tabular}

\begin{tabular}{|llccccc|}
\hline $\begin{array}{l}\text { Table 3A. Forecasts of CPI inflation } \\
\text { Horizon }\end{array}$ & 1 & 4 & 6 & 8 & 10 & 12 \\
& & & & & & \\
Model 4 & & & & & & \\
& & & & & & \\
WTI (HP1) & (a) & & & & & \\
\& Global inflation & 0.988 & 1.001 & $0.801^{* *}$ & $0.929^{*}$ & 1.216 & 1.608 \\
WTI (FD) & (b) & & & & & \\
\& Global inflation & 1.13 & 1.193 & 1.129 & 1.119 & 1.329 & 1.672 \\
\end{tabular}

Note: P-value indicates statistical significance at $10 \%\left({ }^{*}\right), 5 \%\left({ }^{* *}\right)$, or $1 \%\left({ }^{* *}\right)$

\begin{tabular}{|lllllll|}
\hline $\begin{array}{l}\text { Table 3B. Forecasts of Core CPI inflation } \\
\text { Horizon }\end{array}$ & 1 & 4 & 6 & 8 & 10 & 12 \\
Model 4 & & & & & & \\
& & & & & & \\
WTI (HP1) & (a) & & & & & \\
\& Global inflation & 0.984 & $0.853^{* *}$ & $0.581^{* * *}$ & $0.457^{* * *}$ & $0.380^{* * *}$ & $0.349^{* * *}$ \\
WTI (FD) & (b) & & & & & \\
\& Global inflation & 1.081 & 1.066 & $0.861^{* *}$ & $0.653^{* * *}$ & $0.538^{* * *}$ & $0.498^{* * *}$ \\
\hline
\end{tabular}




\section{A3. Rest of the World Countries}

Forecasts of CPI inflation using GDP-based global slack: Austria, Australia, Belgium, Canada, Colombia, France, Germany, Italy, Japan, Mexico, Netherlands, Portugal, South Africa, Spain, Sweden, Switzerland, United Kingdom, United States.

Forecasts of core CPI inflation using GDP-based global slack: Austria, Australia, Belgium, Canada, France, Germany, Italy, Japan, Korea, Netherlands, Spain, Sweden, Switzerland, United Kingdom, United States.

Forecasts of CPI inflation using IP-based global slack: Austria, Australia, Belgium, Canada, Chile, Colombia, France, Germany, Greece, Italy, Japan, Mexico, Netherlands, Portugal, South Africa, Spain, Sweden, Switzerland, United Kingdom, United States.

Forecasts of core CPI inflation using IP-based global slack: Austria, Australia, Belgium, Canada, Chile, France, Germany, Italy, Japan, Korea, Netherlands, Spain, Sweden, Switzerland, United Kingdom, United States.

Forecasts of CPI inflation using global CPI inflation and/or WTI: Austria, Australia, Belgium, Canada, Colombia, France, Germany, Italy, Japan, Mexico, Netherlands, Portugal, South Africa, Spain, Sweden, Switzerland, United Kingdom, United States.

Forecasts of Core CPI using global inflation and/or WTI: Austria, Australia, Belgium, Canada, France, Germany, Italy, Japan, Korea, Netherlands, Spain, Sweden, Switzerland, United Kingdom, United States. 


\section{References}

- Atkeson, A., \& Ohanian, L. E. (2001). Are Phillips Curves Useful for Forecasting Inflation? Federal Reserve Bank of Minneapolis. Quarterly Review-Federal Reserve Bank of Minneapolis, 25(1), 2.

- Ball, L. M. (2006). Has Globalization Changed Inflation? (No. w12687). National Bureau of Economic Research.

- Bernanke, B. S. (2007). Globalization and Monetary Policy. Speech given at the Fourth Economic Summit, Stanford Institute for Economic Policy Research, Stanford, March 2.

- Calvo, G. A. (1983). Staggered Prices in a Utility-Maximizing Framework. Journal of Monetary Economics, 12(3), 383-398.

- Binyamini, A. \& Razin, A. (2007). Flattened Inflation-Output Tradeoff and Enhanced Antiinflation Policy: Outcome of Globalization? (No. w13280). National Bureau of Economic Research.

- Borio, C., \& Filardo, A. (2007). Globalisation and Inflation. BIS Working Papers, No. 227.

- Clark, T. E., \& McCracken, M. W. (2005). Evaluating Direct Multistep Forecasts. Econometric Reviews, 24(4), 369-404.

- D'Agostino, A. \& Surico, P. (2009). Does Global Liquidity Help to Forecast U.S. Inflation? Journal of Money, Credit and Banking, 41(2-3), 479-489.

- Draghi, M. (2015). Global and Domestic Inflation. Speech to the Economic Club of New York, 4. https://www.ecb.europa.eu/press/key/date/2015/html/sp151204.en.html

- Duncan, R. \& Martínez-García, E. (2015). Forecasting Local Inflation with Global Inflation: When Economic Theory Meets the Facts. Federal Reserve Bank of Dallas Globalization and Monetary Policy Institute Working Paper No. 235.

- Edge, R. M., \& Gürkaynak, R. S. (2010). How Useful Are Estimated DSGE Model Forecasts for Central Bankers? Brookings Papers on Economic Activity, 209.

- Fisher, I. (1926). A Statistical Relation between Unemployment and Price Changes. International Labour Review, 13(6), 785-792.

- Fisher, R.W. (2005). Globalization and Monetary Policy. Warren and Anita Marshall Lecture in American Foreign Policy, Federal Reserve Bank of Dallas, November 3.

- Fisher, R. W. (2006). Coping with Globalization's Impact on Monetary Policy. Remarks for the National Association for Business Economics Panel Discussion at the 2006 Allied Social Science Associations Meeting, Boston, January 6.

- Grossman, V., Mack, A., \& Martínez-García, E. (2014). A New Database of Global Economic Indicators. Journal of Economic and Social Measurement, 39(3), 163-197.

- Ihrig, J., Kamin, S. B., Lindner, D., \& Marquez, J. (2010). Some Simple Tests of the Globalization and Inflation Hypothesis. International Finance, 13(3), 343-375.

- Kabukçuoğlu, A., \& Martínez-García, E. (2016a). What Helps Forecast U.S. Inflation?Mind the Gap! In Koç University-TUSIAD Economic Research Forum Working Papers (No. 1615). Koç University-TUSIAD Economic Research Forum.

- Kabukçuoğlu, A., \& Martínez-García, E. (2016b). Inflation as a Global PhenomenonSome Implications for Policy Analysis and Forecasting. Federal Reserve Bank of Dallas Globalization and Monetary Policy Institute Working Paper No. 261.

- Kaplan, R. (2017). Assessment of Current Economic Conditions and Implications for Monetary Policy. Essay by President Robert S. Kaplan, February 13, 2017. https://www.dallasfed.org/news/speeches/kaplan/2017/rsk170213.aspx

- Martínez-García, E. and Wynne, M. A. (2010). The Global Slack Hypothesis. Federal Reserve Bank of Dallas Staff Papers, 10. 
- Milani, F. (2010). Global Slack and Domestic Inflation Rates: A Structural Investigation for G-7 Countries. Journal of Macroeconomics, 32(4), 968-981.

- Milani, F. (2012). Has Globalization Transformed U.S. Macroeconomic Dynamics? Macroeconomic Dynamics, 16(02), 204-229.

- Pain, N., Koske, I., \& Sollie, M. (2006). Globalisation and Inflation in the OECD Economies. Economics Department Working Paper No. 524. Organisation for Economic Cooperation and Development, Paris.

- Stock, J. H., \& Watson, M. W. (1999a). Business Cycle Fluctuations in U.S. Macroeconomic Time Series. Volume 1 of Handbook of Macroeconomics, Chapter 1, pp. 3-64. Elsevier.

- Stock, J. H., \& Watson, M. W. (1999b). Forecasting Inflation. Journal of Monetary Economics, 44(2), 293-335.

- Stock, J. H., \& Watson, M. W. (2003). Forecasting Output and Inflation: The Role of Asset Prices. Journal of Economic Literature, 41(3), 788-829.

- Stock, J. H., \& Watson, M. W. (2008). Phillips Curve Inflation Forecasts. National Bureau of Economic Research (No. w14322).

- Yun, T. (1996). Nominal Price Rigidity, Money Supply Endogeneity, and Business Cycles. Journal of Monetary Economics, 37(2), 345-370. 